\title{
Teknik pemodelan untuk mengurangi perilaku mengganggu pada anak
}

$\Phi$ PROCEDIA Studi Kasus dan Intervensi Psikologi p-ISSN 2302-1462; e-ISSN 2722-7669 ejournal.umm.ac.id/index.php/procedia 2021, Vol 9(2):50-54

DOI:10.22219/procedia.v9i2.15784

(C) The Author(s) 2021

(ㅇ)(ㅇ) 4.0 International license

\author{
Noor Latifah Andina ${ }^{1}$
}

\begin{abstract}
The client is a 7 year old boy who complains of disturbing his friends and relatives at home. The results of the assessment through interviews, observations, psychological tests (CPM) and the Destructive Behavior Disorder Rating Scale (DBD) found that clients have problems with disruptive behavior, with a background problem in learning the wrong way from their environment. The goal of the intervention is to reduce the client's disruptive behavior. The intervention given is Symbolic Modeling Technique using video and role play. The results of the intervention show a decrease in the client's disruptive behavior and are used as guidelines or new, more positive patterns.
\end{abstract}

\author{
Keywords \\ Disruptive behavior, symbolic modeling techniques, students
}

\section{Pendahuluan}

Perilaku mengganggu dapat terjadi pada siapa saja, baik anak-anak normal, mempunyai gangguan, dan bahkan pada orang dewasa. Fenomena ini sering kita temui diberbagai negara, pada penelitian epidemologi dibeberapa negara seperti Kanada, Queesland dan Selandia Baru menunjukan sekitar 5-7 \% anak yang mengalami distruptive behavior (Grainger, 2003). Di Indonesia sendiri untuk data kenakalan anak menurut BPS (Badan Pusat Statistik) pada tahun 2002 tercatat berjumlah 193.155 kasus. Fenomena lain tentang distruptive behavior (perilaku menganggu) yang terjadi pada siswa di kelas dapat dilihat dari salah satu hasil penelitian yang menyatakan bahwa $35,8 \%$ dari sisiwa berperilaku menggangu didalam kelas (Campbell et al., 2013).

Perilaku mengganggu dapat didefinisikan sebagai serangkaian tingkah laku inappropriate yang beragam yang meliputi temper tantrum, merengek atau menangis berlebihan, menuntut perhatian, tidak patuh, menentang, tindakan agresif yang membahayakan diri sendiri atau orang lain, pencurian, berbohong, merusak barang, dan delikuensi. Perilaku menganggu juga digambarkan dengan permasalahan perilaku (externalizing behavior) yang ditujukan pada orang lain atau dunia luar (Crozeir \& Tincani, 2005).

Dalam kasus ini, klien ALN menunjukan perilaku menganggu yang dilakukan di lingkungan sekolah dan rumah. Beberapa perilaku yang dikeluhkan berupa sering melawan orang tua atau guru, serta sering meninggalkan kelas pada saat pembelajaran. Dalam hal ini perilaku distuptive merupakan sebuah hasil belajar tigkah laku yang salah dan diadaptasi oleh anak yang sebelum menguasai keterampilan social yang dibutuhkannya untuk berinteraksi dengan orang lain.

Beberapa faktor yang mempengaruhi perilaku menggangu ini, salah satunya lingkungan yang tidak bermoral. Anak-anak dengan mudah mencontoh perlaku yang ditampakkan oleh lingkungan contohnya yang sering disaksikan melalui media serta masyarakat sekitarnya (Marais \& Meier, 2010). Selain itu, penurunan hubungan yang terjadi dalam keluarga antara orang tua dan anak, yang diikuti dnegan adanya figure otoritas yang menyebabkan terjadinya disfugsi social dengan pengelolaan emosianal atau kognitif, dapat menyebabkan perilaku mengganggu pada anak (Nowak et al., 2013).

Beberapa pelatihan dilakukan untuk mengajarkan anak dalam keterampilan sosial dan cara berinteraksi yang baik telah dilakukan oleh penelitian sebelumnya. Pada kasus ini, praktikan menggunakan intervensi dengan terapi bermain. Bermain merupakan alat atau dasar Pendidikan serta aplikasi terapeutik pada anak (Suryanty, 2011). Selain itu bermaian juga dapat digunakan sebagai media psikoterapi untuk anak yang sering dikenal dnegan sebutan play therapy (Tedjasaputra, 2007). Dengan hal ini praktikan mengambil tema play terapi untuk menumbuhkan empati pada anak dengan perilaku mengganggu yang bertujuan untuk dapat menurunkan perilaku mengganggu pada klien ALN.

${ }^{1}$ CMC Learning Tree: Klinik Tumbuh Kembang Anak, Jakarta

Korespondensi:

Noor Latifah Andina, CMC Learning Tree: Klinik Tumbuh Kembang Anak, Jl. Pantai Indah Selatan 1, Pantai Indah Kapuk, Jakarta Email: nlatifahandina@gmail.com 


\section{Metode Asesmen}

Metode asesmen yang digunakan yaitu sebagai berikut: (1) Wawancara klinis yaitu wawancara yang dilakukan guna mengumpulkan informasi secara mendalam kepada orang tua subjek dan orang terdekat subjek mengenai permasalahan yang terjadi. (2) Observasi berguna untuk mengetahui apa saja perilaku subjek yang nampak saat subjek melakukan aktivitas di sekolah dan di rumah. (3) CPM untuk melihat kapasitas intelektual yang dimiliki klien.

\section{Presentasi Kasus}

Dari hasil asesmen yang telah dilakukan klien merupakan anak laki - laki yang berusia 7 tahun, yang memiliki ciri - ciri fisik seperti berkulit sawo matang yang memiliki tinggi badan $110 \mathrm{~cm}$ dan berat $35 \mathrm{~kg}$. Berdasarkan dari hasil tes inteligensi yang dilakukan dengan menggunakan tes CPM, klien mendapatkan skor IQ grade III termasuk dalam kategori average (rata-rata). Skor ini menunjukan bahwa klien tidak memiliki hambatan dalam kapasitas inteligensinya dan setara dengan kapasitas anak seusianya. Serta dirinya mampu dalam menyelesaikan tugas sekolah, jika dirinya mau dan ingin mengerjakan.

Klien memiliki kakak perempuan, saat ini duduk dibanggu sekolah dasar kelas empat. Klien kerap kali menggoda kakak perempuannya, untuk menjaknya bermaian. Pada masa kehamilan, ibu klien diminta untuk menggugurkan oleh keluarganya dengan alasan rentangan jarak antara kakak dan klien sangat berdekatan. Hal ini yang menjadikan ibu kandung klien berniat dan berusaha untuk menggugurkan janinnya. Namun usaha demi usaha telah dilalui sampai umur kehamilan 2 bulan ibu kandung klien menyerah dan mungkin ini memang sudah kodrat Tuhan. Ibu seorang ibu rumah tangga dan memiliki usaha warung kecil-kecilan dirumahnya. Kehamilan normal sampai klien dilahirkan tidak ada tanda-tanda yang spesifik dalam perkembangan klien.

Ketika klien menduduki usia sekolah taman kanak-kanak, klien menampakan perilaku yang berbeda dari teman sebayanya. Klien sering menampakan perilaku menggangu seperti sangat sukar untuk diam didalam kelas pada saat proses belajar mengajar, sukar mengendalikan emosi, melawan orang dewasa. Hal ini berlanjut sampai klien duduk dibangku sekolah dasar. Selain itu ibu kandung klien mengakui bahwa dirinya sering memarahi klien tersebut. Memarahi dengan nada tinggi dan memukul, karena klien sering membantah perkataan dan lebih memilih bermain dengan teman dilingkungannya. Teman sepermainan klien di lingkungan rumah merupakan anak yang lebih besar dari dirinya. Klien mengakui bahwa dirinya sering disuruh untuk mencuri dan disuruh untuk berbohong kepada orang tua. Selain itu ia diajarkan dengan perilaku merokok. Pembelajaran yang salah melalui pengamatan (Observational Learning), perilaku yang salah diimitasi oleh klien melalui temannya, yang berdampak pada perilaku kurang baik.

Ibu kandung klien menyatakan bahwa klien tidak menyukai ketika dipeluk dan dicium, mulai dari umur 5 tahun, klien menolak ketika orang tua ingin memeluk dan menciumnya. Sering kali sang ibu ingin memeluk dan mencium tapi respon klien menolak dan memarahi si Ibu. Ketika praktikan menanyakan langsung ke klien alasannya tidak mau dipeluk, klien hanya senyum dan menjawab malu dilihat orang dipeluk. Klien hanya sering mengamati bahwa sang ibu, nenek memeluk sang kakak (perempuan), ia memahami ketika laki-laki (dirinya) tidak pantas dipeluk oleh perempuan.

Hal ini diperkuat dengan sikap kakek yang kaku, klien tidak pernah melihat kakek yang memeluk nenek atau memeluk ibu dan kakak kandungnya. Klien mengimitasi perilaku kakek dengan tidak berpelukan dengan perempuan dan itu menjadi sebuah pemikiran bahwa hal tersebut tidak pantas dan membentuk perilaku malu.

Perilaku klien tidak terlepas dari proses pembelajaran yang salah dari lingkungan sekitarnya. Dalam konsep social learing theory, yang didasarkan pada konsep saling menentukan (reciprocal determinism), tanpa penguatan dan pemikiran diri. Dalam hal ini klien melihat dan mencontoh perilaku yang ditimbulkan oleh lingkungannya sehingga mengadaptasi perilaku yang salah untuk dilakukan dikehidupannya. Dalam kasus ini, pembentukan perilaku yang salah, klien dapat belajar dengan mengadaptasi perilaku yang dapat diamati yakni perilaku teman dan perilaku orang tua yang sering marah dan kemudian mengulang perilaku tersebut pada perubahan atau mendapatkan situasi yang sesuai dengan perilaku yang dilihat sebelumnya oleh klien.

\section{Diagnosis dan Prognosis}

Klien memiliki permasalahan psikologis yang tergolong dalam DSM V dengan indikasi other specified distruptive, impulse-control, dan conduct disorder(312.89) dengan problem perilaku mengganggu.

Klien memiliki prognosis yang baik untuk keberhasilan intervensi, yang ditandai dengan adanya dukungan dari keluarga, serta adanya keinginan yang baik dari klien untuk belajar, serta mengikuti proses terapi dengan baik dan kooperatif terhadap praktikan serta patuh pada aturan yang telah disepakati bersama.

\section{Intervensi}

Dalam intervensi yang dilakukan pada kasus ini meerupakan terapi bermain dnegan Teknik modeling. Teknik modeling yang dipakai merupakan Teknik pemodelan simbolik, klien diminta untuk melihat dari sebuah video, gambar/cerita, serta modeling terbuka dengan role play dimana praktikan akan mencontohkan perilaku dan klien diminta untuk menirukan perilaku tersebut. Teknik ini terbentuk dalam sebuah rancangan permainan yang disebut dengan 
modelling empaty play therapy yang dirancang sendiri oleh praktikan dengan menggunakan media ulartangga modifikasi dengan tambahan contoh perilaku didalamnya. Adapun beberapa permainan dan aturan yang telah dilakukan yang terbagi dalam 7 sesi yang dirincikan sebagai berikut :

Sesi I: Membangun raport. Terapis membangun raport degan klien dan mengidentifikasi permasalahan yang ada pada subjek. Setelah permasalahan teridentifikasi, klien dan terapis akan membicarakan mengenai proses intervensi yang akan dilakukan serta tujuan berdasarkan perubahan yang diiinginkan oleh klien.

Sesi II: Modeling simbolik. Pada sesi menonton video (modeling simbolik) terapis memodelkan sebuah tontonan yang baik terkait perilaku yang baik yang dilakukan disekolah dan dirumah, baik berperilaku terhadap guru, orang tua, dan teman sebaya.

Sesi III: Mengulang cerita pada video simbolik. Pada sesi ini terapis ingin mengenalkan dan ingin mengetahui apa saja yang diketahui klien terkait perilaku baik yang harus dilakukan ketika disekolah, dirumah dan ketika bermain dengan teman sebaya. Hal ini diingukap dengan cara menanyakan langsung ketika berada di sebuah situasi yang dihadapi maka akan berperilaku seperti apa dan bagaimana cara menanganinya. Dalam hal ini terapis mengulang cerita yang telah ditonton pada sesi sebelumnya kepada klien dan temannya.

Sesi IV: Permainan ular tangga. Pada permainan ini yang termasuk pada sesi empat sampai enam, terapis menyediakan permainan ular tangga yang besar ukran 3 X 3 meter. Isi dari permainan ular tangga ini merupakan beberapa perilaku yang baik dan perilaku yang buruk. Ketika perilaku baik maka terdapat tangga untuk bisa menaiki ketahap selanjutnya, namun jika perilaku buruk maka akan ada perosotan untuk turun. Pada aturan bermain, terapis sengaja memberikan beberapa aturan yang harus ditaati oleh pemain, yakni yang dibagi menjadi tiga tahapan bermaian. Pada tahap pertama permainan klien diminta untuk mengeksplorasi atau mencari perilaku mana saja yang baik dan perilaku mana saja yang buruk. Pada tahapan kedua klien diminta untuk mengetahui perilaku itu baik atau buruk (Yes or No), sedangkan perilaku yang ketiga klien harus memperagakan perilaku yang baik terhadap orang tua atau teman. Semua tahapan yang dilalui dengan proses feedback setelah permainan berlangsung.

Sesi V: Evaluasi dan terminasi. Dilanjutkan dengan sesi evaluasi, dimana praktikan mengevaluasi perkembangan dan meminta klien untuk memaparkan apa yang telah klien ketahui dan pelajaran apa saja yang didapatkannya dalam proses terapi berlangsung. Dilanjutkan dengan sesi terminasi untuk pengakhiran proses terapi dan memaparkan kepada klien dan temannya karena proses terapi telah berakhir dan telah usai, selain itu praktikan memotivasi klien untuk bersikap baik terhadap ibu dan kakak serta teman sekitarnya.

\section{Hasil dan Pembahasan}

\section{Hasil}

Hasil intervensi yang telah dilakukan kepada klien, klien mengalami perkembangan empati dan berpengaruh terhadap perilaku yang ditunjukan selama proses intervensi berlangsung. Orang tua klien dan guru kelas menjelaskan bahwa klien sangat sulit untuk mengikuti pelajaran, sering tidak mendengarkan guru dan sering mengamuk ketika tidak menuruti permintaannya.

Setelah dilaksanakan proses intervensi tampak adanya perubahan seperti klien mampu mengikuti pelajaran dalam kelas, tidak berkeliaran keluar kelas dan menggangu kelas lain. Walaupun sesekali klien jalan dan tidak menyelesaikan tugasnya. Namun frekuensi yang dilakakukan berkuang dari yang awalnya disetiap pelajaran yang diajarkan oleh guru kelasnya diikuti dan sekarang klien tidak mengikutinya kekelas lain. Selain itu perilakunya dirumah, klein sering ngambek dan menangis meronta-ronta ketika keinginannya tidak terpenuhi, namun setelah dilakukan intervensi walaupun klien menampakan perilaku tidak suka atau marah, klien tetap masih mau mengalihkan marahnya dengan perilaku lain dan tidak menampakan perilaku meronta-rontanya.

Perubahan perilaku juga terlihat dari hasil observasi yang dilakukan dengan self report yang diberikan kepada orang tua (rumah) dan guru kelas (sekolah) setelah intervensi berlangsung. Terlihat adanya berubahan yang signifikan dari perilaku sebelum dan sesudah dilakukan terapi.

Gambar 1 menunjukkan adanya penurunan perilaku. Dalam hal ini klien menampakan perubahan dari setiap sesi intervensi, klien terlihat mengamati setiap pemberian intervensi mulai dari menonton video perilaku baik, permaian ular tangga serta role play perilaku baik. Role

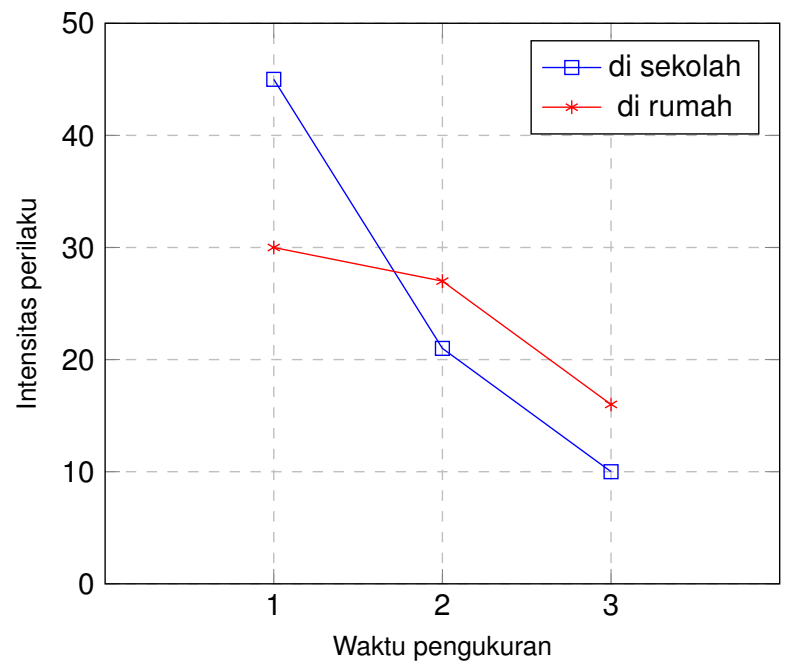

Gambar 1. Perubahan perilaku anak sebelum intervensi (1), setelah intervensi (2) dan waktu follow-up berdasarkan pengamatan di sekolah oleh guru dan di rumah oleh orang tua 
play perilaku baik yang dicontohkan oleh praktikan dan diikuti oleh klien. Terlihat perubahan dari grafik sekolah sangat tinggi dapat berkurang setelah dilakukan intervensi

\section{Pembahasan}

Pada proses intervensi berlangsung, disetiap sesi klien menunjukan perubahan yang signifikan terhadap perilakunya terhadap teman permainannya. Permainan dilakukan dilingkungan rumah dengan teman sepermainannya. Pada sesi awal klien menunjukan adanya perilaku mendominasi, klien selalu ingin unggul dan tidak mau mengalah dengan teman lainnnya. Namun adanya peraturan yang harus dipatuhi dalam permainan, yakni pemilihan pemain pertama yang memainkan permainan. Pada saat itu klien mendapatkan urutan terakhir dan klien ingin memainkan diawal, praktikan menjelaskan bahwa peraturan permaian yang telah disepakati harus sesuai dan klien harus menunggu pemain yang lebih dulu darinya. Emosi yang fluktuatif yang ditampakan oleh klien pada setiap sesi yang terlihat dari perkembangan perubahan perilakunya.

Pada proses feedback yang dilakukan, klien pada awalanya diam dan hanya mengamati situasi, serta mendengarkan pendapat teman- temannya yang mengikuti permaiana tersebut. Anak dilatih untuk memperoleh pengalaman- pengalaman yang dapat diaplikasikan dalam kehidupan nyatanya. Pada proses permainan yang mengajarkan kepada perilaku baik yang dimiliki oleh klien. Aktifiats juga sangat erat kaitannya dengan proses pembelajaran. Pengetahuan yang diciptakan dari transpormasi dan pengalaman, dimana pengetahuan merupakan hasil dari kombinasi penyerapan dan transformasi pengalaman (Kolb, 1999).

Selaian itu, proses intervensi ini tidak terlepas oleh peran orang tua didalamnya. Orang tua yang sangat kooperatif selama proses intervensi berlangsung. Orang tua sangat mengerti dan mengikuti saran praktikan pada proses intervensi berlangsung. Perubahan perilaku yang dahulunya ibu sering memarahi klien dengan pukulan dan dengan nada tinggi, sedikit demi sedikit dihilangkan. Orang tua mengakui bahwa perilakunya saat ini kurang pantas dilakukan terhadap klien. Orang tuang memiliki pengaruh besar terhadap perkembangan tingkah laku serta emosi yang ditampakan oleh anak, serta beberapa pola asuh yang kurang tepat, dapat memperkuat perilaku destruptive pada anak.

Pembelajaran akan moral norma dalam kehidupan perlu dan snagat penting diajarkan dan diperlihatkan oleh orang tua. Keluarga merupakan peran yang paling berpengaruh pada perkembangan individu (Marais \& Meier, 2010). Dengan hal tersebut intervensi ini berjalan lancer tidak terlepas dari peran orang tua yang dapat mengerti dan memahami perilakunya untuk lebih selective dalam pemilihan perilaku yang ditampakan terhadap anak.

\section{Kesimpulan dan Saran}

\section{Kesimpulan}

Dari hasil asesmen awal yang telah dilakukan pada klien, orang tua dan guru yang didapatkan bawa perilaku yang dimunculkan merupakan sebuah proses pembelajaran pada pengamatan yang kurang tepat. Intervensi yang bertujuan agar klien lebih mengetahui, mengamati, perilaku yang baik untuk diatapsi ke kehidupannya Proses intervensi yang berjalan baik sehingga menumbuhkan perubahan perilaku yang lebih positif oleh klien. Dapat disimpulkan bahwa proses intervensi berhasil dan membawa dampak positif bagi klien.

\section{Saran}

Bagi orang tua klien mampu lebih memotivasi klien dan lebih menunjukan akan penghargaan atau apresiasi segala bentuk perilaku baik yang mulai dilakukan oleh klien. Serta lebih menunjukan bahwa sosok orang tua mampu lebih mendengarkan apa keinginan dan apa yang dibutuhkan oleh klien pada saat ini. Serta bagi sekolah agar mampu memahami bahwasannya pada setiap kondisi anak berbeda dan setiap perubahan pada anak-anak juga berbeda.

Untuk penelitian selanjutnya agar lebih menekankan pada faktor yang menunjang dari berjalananya proses intervensi. Kerjasama antara klien dan orang tua merupakan suatu kemudahan pada proses pemberian intervensi ini. Serta mengharapkan praktikan selanjutnya untuk lebih melakukan intervensi mendalam di sekolah.

\section{Referensi}

Bachner, H. A. \& Orwig, J. F. (2010). Moving beyond discipline of disruptive behavior: recognizing and treating the effects of trauma on adolescents. Compelling Counseling Interventions.pp 1-10. https://www.counseling. org/resources/library/VISTAS/2008-V-Print-completePDFs-for-ACA/Bachner-Orwig_Article_1.pdf

Bangal, V. B., Sachdev, S. Y., \& Suryawanshi, M. (2013). Disruptive behavior in health care setting- reasons, implications and remedial measures. International Journal of Biomedical and Advance Research, 4(5),1-3. https://doi.org/10.7439/ ijbar.v4i5.368

Campbell, A. \&, Rodrigues, B. J,. Anderson, C., \& Barnes, A,.(2013). Effects of a tier 2 on classroom distruptive behavior and academic engagement. Journal of Curricululum and Instruction,7(1), 32 - 54. https://doi.org/10.3776/joci.2013. v7n1p32-54

Crozeir, S. \& Tincani, M. J. (2005). Using a modified social story to decrease distruptive behavior of a child with autism. Focus on autism and other developmental disabilities, 20(3), 150157. https://doi.org/10.1177/10883576050200030301

Grainger, J. D. (2003). Nerva and the Roman succession crisis of AD 96-99. Routledge. 
Kolb, D.A., Boyatzis, R.E., \& Mainemelis, C. (1999). Experiental Learning Theory: Previous research and new directions. Case Western Reserve University

Marais, P. \& Meier, C. (2010). Disruptive behavior in the foundation phase of schooling. South African Journal of Education EASA,30, 41-57. https://doi.org/10.4314/saje. v30i1.52601

Motamedi, M. et al. (2008). Effects of parent training on salivary cortisaol in children and adolescents with disruptive behavior disorder. Journal of Research in Sciences, 13(2), 69-74. https://doi.org/10.15700/saje.v30n1a315

Murphy, S. P. (2006). Dealing with disruptive students: a faculty perspective. College of Lake County.
Nowak, M., Gaweda, A., Jelonek, I., \& Kozik, M. J. (2013). The disruptive begavior disorders and the coexisting deficits in the context of theories describing family relations. Archives of Psychiatry and Psychotherapy, 1, 61-65. https://psycnet. apa.org/record/2013-45557-007

Suryanty. (2011). Pengaruh terapi bermain mewarnai dan origami terhadap tingkat kecemasan sebagai efek hospitalisasi pada anak usia prasekolah di RSUD dr. R. Goetheng Tarunadibrata Purbalingga. Jurnal Kesehatan Samodra Ilmu, 2, 1-9. https://digilib.ump.ac.id/files/disk1/16/jhptumpa-suryantiso-761-1-pengaruh-.pdf

Tedjasaputra, Maykes. (2007). Bermain,mainan dan permainan. Grasindo. 